\title{
Descriptive epidemiology of objectively-measured, free-living sleep parameters in a rural African setting
}

\author{
Ian Cook ${ }^{1^{*}}$ (D, Matlawa Mohlabe ${ }^{2}$ and Marianne Alberts²
}

\begin{abstract}
Objectives: To investigate the descriptive nature of objectively-measured, free-living sleep quantity and quality, and the relationship to adiposity, in a rural African setting in 145 adults ( $\geq 40$ years, female: $n=104$, male: $n=41$ ). Wristmounted, triaxial accelerometry data was collected over 9 days. Measures of sleep quantity and quality, and physical activity were extracted from valid minute-by-minute data. Adiposity indices were body-mass-index, waist circumference and conicity index. Self-reported data included behavioural, health and socio-demographic variables. Community consultation followed the quantitative data analyses, for validation and interpretation of findings.

Results: Females had more nocturnal sleep than males (7.2 vs. $6.8 \mathrm{~h} /$ night, $p=0.0464$ ) while males recorded more diurnal sleep time $(p=0.0290)$. Wake after sleep onset and number of awakenings were higher in females, and sleep efficiency was higher in males ( $p \leq 0.0225)$. Sleep indices were generally similar between weekdays and weekends, except for sleep fragmentation index $(p=0.0458)$. Sleep quantity, but not sleep quality was independently and inversely associated with adiposity ( $p=0.0453$ ). Physical activity and morbidity measures were significantly and consistently associated with sleep and adiposity measures $(p<0.0458)$. The preliminary qualitative data suggests that future studies should include more detailed data around contextual issues of sleep (social, cultural, economic, environment).
\end{abstract}

Keywords: Body composition, Anthropometry, Accelerometer, Actigraphy, Movement monitor, Measurement

\section{Introduction}

Sleep is recognized as an important lifestyle contributor to morbidity and mortality [1]. While extensive Sleep Health Epidemiology literature exists for high income countries, there is a need of especially objective measures of sleep, such as actigraphy, from low and middle-income countries, [2,3]. Within the South African context to date, studies have exclusively utilized self-report measures in adult populations [4-12]. Hence, there is a dearth of objectively-measured sleep data from South African, and specifically rural African settings [3, 13].
Self-reported long sleep time for rural South Africans [810], requires confirmation using objective measures of sleep duration. A recent study found a significant, inverse relationship between self-reported sleep duration and adiposity in a rural African setting [14]. Given the lack of objectively-measured, free-living sleep parameters in any South African setting, the objective of this study was to use wrist-actigraphy to derive sleep parameters in a rural African setting during a cross-sectional survey, and thus extend the findings of self-report sleep duration and the relationship to adiposity $[4-12,14]$.

\footnotetext{
*Correspondence: ian.cook@ul.ac.za

1 Physical Activity Epidemiology Laboratory (EDST), University of Limpopo

(Turfloop Campus), Sovenga, PO Box X1106, Limpopo 0727, South Africa

Full list of author information is available at the end of the article
}

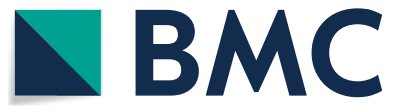

(c) The Author(s) 2020. This article is licensed under a Creative Commons Attribution 4.0 International License, which permits use, sharing, adaptation, distribution and reproduction in any medium or format, as long as you give appropriate credit to the original author(s) and the source, provide a link to the Creative Commons licence, and indicate if changes were made. The images or other third party material in this article are included in the article's Creative Commons licence, unless indicated otherwise in a credit line to the material. If material is not included in the article's Creative Commons licence and your intended use is not permitted by statutory regulation or exceeds the permitted use, you will need to obtain permission directly from the copyright holder. To view a copy of this licence, visit http://creativeco mmons.org/licenses/by/4.0/. The Creative Commons Public Domain Dedication waiver (http://creativecommons.org/publicdomain/ zero/1.0/) applies to the data made available in this article, unless otherwise stated in a credit line to the data. 


\section{Main text \\ Methods \\ Dikgale health and demographic surveillance system site (DHDSS) sample [15]}

A convenience sample of 167 adult participants was recruited from the AWI-Gen Phase 1 Study cohort ( $\geq 40$ years), the methodological details of which are reported in detail elsewhere [14, 16]. Trained field workers collected self-reported, measured and biological data from participants by means of questionnaires, anthropometry, ultrasound scans, and venipuncture $[14,16]$. We calculated body mass index (BMI, $\mathrm{kg} / \mathrm{m}^{2}$ ) and conicity index (CI) [17]. The latter measure allows a single-measure of body shape to be used in multivariate analyses. Questionnaire data included behavioural, health and socio-demographic variables and is reported in detail elsewhere $[14,16]$. The ultrasound scans and blood-derived variables were not considered for this analysis.

\section{Accelerometer data collection and data reduction}

Participants wore a small, light-weight, wrist-worn triaxial accelerometer for 9 days (ActiGraph wGT3X-BT, Actigraph, LLC, Pensacola, FL, 2013) [18-21]. Prior to use, the monitors were connected to an IBM-compatible computer via USB interface and initialized to sample at $30 \mathrm{~Hz}$, using proprietary software (Actilife 6.13.4, Actigraph, LLC, Pensacola, FL, 2009-2015). The monitors were affixed with a proprietary woven nylon wristband on the non-dominant wrist, and unless there was to be a sustained period of water immersion, participants were requested not to remove the monitors. On the 9th day, the monitors were collected from the participants. Thereafter, the raw recorded data was downloaded from the monitors onto an IBM-compatible computer and stored for later analysis. Prior to re-use of the monitors, the batteries were fully recharged and the memory cleared of previous data. The wrist straps were washed using a disinfectant solution, rinsed in water and air-dried.

Using proprietary software (Actilife 6.13.4, Actigraph, LLC, Pensacola, FL, 2009-2015), valid data (at least 1 weekday and 1 weekend day) was obtained by first converting downloaded, raw data files to $60 \mathrm{~s}$ epochs. Thereafter, the Cole-Kripke sleep scoring algorithm was used to determine minute-by-minute asleep/awake status [22], and the Actilife-modified Tudor-Locke algorithm to identify sleep periods [23, 24]. Valid wear-time was evaluated using the Choi algorithm [25, 26], with sleep time marked as wear time, and a valid day requiring $\geq 10 \mathrm{~h}$ of wear time. Vector Magnitude (VM)- and Ambulationdefined physical activity variables were defined as counts/ day and counts/minute, and steps/day and steps/minute, respectively [27]. Sleep indices included Total Sleep Time
(TST), Sleep Efficiency (SE), Wake After Sleep Onset (WASO) and Sleep Fragmentation Index (SFI) [28-30].

Valid physical activity and sleep data was downloaded in a summarised and detailed format in Microsoft Excel ${ }^{\mathrm{TM}}$ files and additional variables were extracted: diurnal and nocturnal sleep time, sleep periods during defined hours, and sleep variation across days (within-person total sleep time SD). Diurnal and nocturnal periods were defined as 06h00-18h00 and 18h01-05h59, respectively. The number of sleep periods initiated between 00h01 and 05h59 defined an additional sleep quality indicator. A sleep period falling completely within the period 06h00-18h00 was defined as potentially a "daytime napping" period. Sufficient sleep quantity and quality were defined as 7-9 h [31] and SE $\geq 85 \%$, respectively [32]. Data was then imported into statistical software for further analyses.

\section{Statistical analyses}

Descriptive statistics comprised means (one standard deviation), medians (interquartile range) and frequencies. Relationships between categorical variables were examined through the Chi square Test. For continuous data, independent and dependent $t$ - tests examined differences between the sexes and weekday/weekend days and where required, the appropriate non-parametric test was employed. Due to non-normality, continuous variables were transformed to quantiles as required. Bivariate relationships were examined using correlation coefficients.

Multiple linear regression models were examined for predictors of sleep indices (TST, SE, WASO, SFI) and body composition measures (waist circumference and BMI) using selected socio-demographic, behavioural and biological variables. Forced and Backward selection ( $p$ in $=0.05, p$ out $=0.10)$ models were employed. Separate sex-specific analyses were run, specifically to include parity in the female analysis. For multivariate adiposity analyses TST and SE were used in forced models, while TST, SE, WASO, SFI were entered in selection models.

To analyze the trend across days for objectively-measured sleep indices, the day-by-day data was analysed by fitting a mixed-effects model (Fixed effect, Type III, Restricted Maximum Likelihood), using a compound symmetry covariance matrix. Missing values were considered missing completely at random. The Geisser-Greenhouse correction was adopted throughout. Multiple comparisons tests (Tukey) compared sleep indices across each day.

Data were analysed using appropriate statistical software (IBM SPSS Statistics: Release 25 IBM Corporation, Armonk NY, 2017 and GraphPad Prism: version 8.3.0, GraphPad Software, La Jolla CA, 2019). Significance for all inferential statistics was set at $p<0.05$. 


\section{Informant consultation}

To add contextual detail to the quantitative results, we obtained feedback from DHDSS fieldworkers $(n=2)$ and the community engagement officer through an interview [33]. Key findings were discussed and informants were encouraged to provide feedback, which was captured via notes. After the interview, the notes were distributed for confirmation.

\section{Results}

Of the 167 raw data files, 157 had valid data for at least one weekday and one weekend day. Once combined with the questionnaire and body composition data, 145 had complete data. Participants averaged 7.54 (0.61) days of valid data, with $94.3 \%$ (7.6) wear time and $5.7 \%$ (7.6) of non-wear time. The number of weekdays and weekend days with valid data was $5.9(0.5)$ and $2.0(0.2)$ days, respectively. Except for self-reported PA $(p=0.002)$, there were no significant differences in socio-demographic, behavioural or biological variables between the study participants and the full DHDSS AWI-Gen sample [14]. There was no significant difference between participants with 7 days $(n=90)$ versus $<7$ days $(n=55)$ of accelerometry data across socio-demographic, behavioural and biological variables $(p \geq 0.128)$, except for fruit and vegetable intake $(\mathrm{p}=0.013)$.

A total of 1148 sleep periods was recorded, of which 13 (1.1\%) fell completely within the period 06h00-18h00. Four of these sleep periods were recorded by HIV + participants. Three of these four periods (309-340 min, 5-14 awakenings, WASO 28-57 $\mathrm{min}$ ) were recorded by one $\mathrm{HIV}+$ male ( 56 years, $19.2 \mathrm{~kg} / \mathrm{m}^{2}$ ).

In a comparison between HIV + and HIV-participants, only WASO (55 vs. $49 \mathrm{~min}$, respectively) and number of awakenings (NOA) (16 vs. 14 awakenings, respectively) were significantly different $(p \leq 0.0404)$.

Females displayed significant levels of adiposity while no males were obese $(p<0.0001)$ (Table 1$)$. Females also displayed higher prevalence of hypertension, consumption of sugar-sweetened beverages, and levels of objectively measured PA $(p \leq 0.0050)$. However, significantly more males than females reported current use of alcohol $(p<0.0001)$ (Table 1$)$.

Sleep quantity (nocturnal) was significantly higher in females $(p \leq 0.0464)$, while sleep quality indices were significantly poorer in females $(p \leq 0.0290)$ (Table 2$)$. Males slept more during the day $(p=0.0290)$, were in bed more than 90 min earlier than females $(p=0.0016)$ and had significantly more sleep periods starting between 00:0105:59 $(p=0.0084)$ (Table 2). There was no association between sufficient sleep categories for TST or nocturnal sleep time, and gender or day of the week $(p \geq 0.4904)$ (Table 2).

Sleep quality (SFI) was significantly poorer on weekdays $(p=0.048)$ and significantly more sleep periods starting between 00:01-05:59 $(p=0.0443)$ occurred on weekdays (Table 2).

There was no significant association between selfreported TST (Table 1) and objectively-measured TST (Table 2) $(p \geq 0.0568)$.

Significantly more nocturnal sleep time was accrued on Tuesday and Wednesday compared with the weekend $(p \leq 0.0409)$ (Fig. 1A), and a similar pattern was found for TST (Fig. 1B). Less than $40 \%$ of the participants slept 7-9 h (Fig. 1B). Generally NOA and WASO were significantly higher on Tuesday-Wednesday, compared with the Saturday-Monday ( $p \leq 0.0451)$ (Fig. 1C-D). Activity counts during sleep were significantly higher on Wednesday compared with Saturday $(p=0.0076)$ (Fig. 1E) and $60-70 \%$ of participants achieved $\mathrm{SE} \geq 85 \%$ (Fig. 1F). There were no significant differences across days for diurnal sleep time $(p=0.3463)$, any fragmentation index ( $p \geq 0.2828)$, or length of awakenings ( $p=0.3463)$.

Except for TST, sleep indices were not associated with adiposity measures in multivariate analyses (Additional file 1: Tables S1-S2, see Additional file 1). In contrast, current morbidity status, socio-demographic indices and lifestyle factors were significantly associated with adiposity indices (Additional file 1: Table S1-S2, see Additional file 1$)$. In female models, parity was not related to adiposity level $(p>0.05)$.

PA was significantly associated with TST and SE $(p \leq 0.0077)$, while socio-economic and-demographic indices were significantly associated with sleep indices $(p \leq 0.0389)$ (Additional file 1: Table S3-S4, see Additional File 1). In female models, parity was significantly associated with TST and SE $(p \leq 0.0430)$ (Additional file 1: Table S4, see Additionalf 1).

PA was significantly related to WASO and SFI in forced and backward-selection sleep models $(p \leq 0.0360)$.

The qualitative results provide insight into the quantitative trends (see Additional file 2). Health outcomes (adiposity) and sleep patterns were associated with a number of themes; gender roles, cultural preferences/ practices and community activities, education and living conditions.

\section{Discussion}

This analysis is novel in that, as far as the authors are aware, this is the first free-living, objectively-measured sleep data from a South African setting.

The main findings of this analysis were first that females tended to sleep more than males, although sleep quality tended to be worse in females. Second, sleep variables 
Table 1 Descriptive statistics of demographic, behavioural and biological characteristics by sex

\begin{tabular}{|c|c|c|c|c|}
\hline & All $(n=145)$ & Female $(n=104)$ & Male $(n=41)$ & $P$ value \\
\hline \multicolumn{5}{|l|}{ Socio-demographic } \\
\hline Age (years) & $52.6(7.0)$ & $52.1(6.7)$ & $54.1(7.5)$ & 0.1455 \\
\hline Marital status (Married/Co-habiting) $)^{b}$ & $55.9(81)$ & $55.8(58)$ & $56.1(23)$ & 0.6342 \\
\hline Level of education (formal education) ${ }^{b}$ & $95.2(138)$ & $95.2(00)$ & $95.1(39)$ & 0.9966 \\
\hline Employed $(\text { Yes })^{b}$ & $26.2(38)$ & $26.0(27)$ & $26.8(11)$ & 0.9148 \\
\hline SES Quintile & $3.6(1.3)$ & $3.6(1.3)$ & $3.5(1.3)$ & 0.5496 \\
\hline \multicolumn{5}{|l|}{ Housing density ${ }^{\mathrm{a}}$} \\
\hline People/room & $0.8(0.8)$ & $0.9(0.7)$ & $0.7(0.7)$ & 0.0430 \\
\hline People/bedroom & $1.5(1.3)$ & $1.7(1.3)$ & $1.3(1.0)$ & 0.0280 \\
\hline \multicolumn{5}{|l|}{ Behavioural } \\
\hline \multicolumn{5}{|l|}{ Diet $^{\mathrm{a}}$} \\
\hline Fruit and vegetable intake (servings/day) & $1.3(0.9)$ & $1.3(1.2)$ & $1.1(0.4)$ & 0.0710 \\
\hline Sugar sweetened beverages (servings/day) & $0.3(0.1)$ & $0.3(0.1)$ & $0.3(0.0)$ & 0.0050 \\
\hline Tobacco use (current smoke and/or smokeless; Yes) & $48.3(70)$ & $45.2(47)$ & $56.1(23)$ & 0.2366 \\
\hline Alcohol use (current; Yes) & $20.0(29)$ & $8.7(9)$ & $48.8(20)$ & $<0.0001$ \\
\hline \multicolumn{5}{|l|}{ Self-reported physical activity ${ }^{a}$} \\
\hline MVPA (minutes/week) & $990(968)$ & $1020(1005)$ & $840(1170)$ & 0.2740 \\
\hline \multicolumn{5}{|l|}{ Self-reported sleep } \\
\hline Sleep (hours/night) & $9.2(1.6)$ & $9.1(1.4)$ & $9.5(1.8)$ & 0.1924 \\
\hline Weekday sleep (hours/night) & $8.9(1.7)$ & $8.7(1.5)$ & $9.4(2.0)$ & 0.0694 \\
\hline Weekend sleep (hours/night) & $9.8(2.2)$ & $9.8(2.3)$ & $9.7(1.8)$ & 0.8137 \\
\hline \multicolumn{5}{|l|}{ Objectively-measured physical activity } \\
\hline VM counts/day $\left(\times 10^{6}\right)$ & $2.33(0.70)$ & $2.47(0.63)$ & $1.99(0.76)$ & 0.0007 \\
\hline VM counts/minute & $1621(486)$ & $1715(435)$ & $1383(530)$ & 0.0007 \\
\hline Steps per day & $14,416(4637)$ & $14,140(3718)$ & $15,116(6411)$ & 0.3645 \\
\hline Step cadence (steps/minute) & $10.0(3.2)$ & $9.8(2.6)$ & $10.5(4.5)$ & $0.3652)$ \\
\hline \multicolumn{5}{|l|}{ Biological } \\
\hline Waist circumference (cm) & $90.0(1.6)$ & $93.5(1.6)$ & $81.2(10.0)$ & $<0.0001$ \\
\hline Body mass index $\left(\mathrm{kg} / \mathrm{m}^{2}\right)$ & $28.1(7.8)$ & $30.6(7.6)$ & $21.9(3.9)$ & $<0.0001$ \\
\hline \multicolumn{5}{|l|}{ Body mass index categories ${ }^{b}$} \\
\hline Under- normal weight $\left(<25 \mathrm{~kg} / \mathrm{m}^{2}\right)$ & $37.2(54)$ & $24.1(25)$ & $70.7(29)$ & $<0.0001$ \\
\hline Overweight $\left(25-29.99 \mathrm{~kg} / \mathrm{m}^{2}\right)$ & $24.1(35)$ & $22.1(23)$ & $29.3(12)$ & \\
\hline Obese $\left(\geq 30 \mathrm{~kg} / \mathrm{m}^{2}\right)$ & $38.6(56)$ & $53.8(56)$ & $0.0(0)$ & \\
\hline HIV status $(Y e s)^{b}$ & $22.1(32)$ & 21. (22) & $24.4(10)$ & 0.6722 \\
\hline Hypertension $(Y e s)^{b}$ & $50.3(73)$ & $55.8(58)$ & $36.6(15)$ & 0.0375 \\
\hline Diabetes mellitus $(Y e s)^{b}$ & $4.1(6)$ & $3.8(4)$ & $4.9(2)$ & 0.5451 \\
\hline Parity & - & $4.2(1.8)$ & - & \\
\hline
\end{tabular}

Italicized $p$ values are significant $(p<0.05)$

Data reported as mean (SD)

HIV Human Immunodeficiency Virus, MVPA Moderate to vigorous physical activity, SES Socio-economic status, VM Vector magnitude

a Median (IQR) or ${ }^{\mathrm{b}} \%$ (n)

were generally similar between weekdays and weekend days. Third, only one sleep variable was associated with measures of adiposity, while PA variables were significantly related to adiposity and sleep variables. Fourth, morbidity measures were consistently associated with adiposity and sleep variables.
To date, the average self-reported sleep time for black South Africans (male/female, rural/urban) is $\pm 9 \mathrm{~h}$ (range: 8-10.4 h) [4, 6, 8-12, 14]. While some studies have reported gender differences for TST in rural samples (females $>$ males) $[4,14]$, Peltzer et al. found the reverse (males $>$ females) [8], and others found no gender differences, specifically in urban samples $[9,12]$. In 
Table 2 Objective measures of sleep quantity and -quality indices across sex and day of the week

\begin{tabular}{|c|c|c|c|c|c|c|}
\hline & \multicolumn{3}{|l|}{ Sex } & \multicolumn{2}{|l|}{ Day of the week } & \multirow[t]{2}{*}{ P-values } \\
\hline & Female $(n=104)$ & Male $(n=41)$ & P-values & Weekday $(n=145)$ & Weekend $(n=145)$ & \\
\hline \multicolumn{7}{|l|}{ Quantity } \\
\hline \multicolumn{7}{|l|}{ Sleep time (minutes/day) } \\
\hline Total & $458(67)$ & $454(105)$ & 0.8175 & $456(86)$ & $458(91)$ & 0.6828 \\
\hline Diurnal ${ }^{a}$ & $15(37)$ & $20(59)$ & 0.1560 & $10(43)$ & $14(39)$ & 0.6110 \\
\hline Nocturnal & $433(60)$ & $410(72)$ & 0.0464 & $427(70)$ & $427(76)$ & 0.9380 \\
\hline Nocturnal/Total sleep (\%) & $95.0(5.7)$ & $91.6(9.9)$ & 0.0463 & $94.4(7.7)$ & $93.8(8.9)$ & 0.3553 \\
\hline \multicolumn{7}{|l|}{ Diurnal sleep time $\geq 1 \mathrm{~min}^{\mathrm{c}}$} \\
\hline Prevalence $^{\mathrm{b}}$ & $83.7(87)$ & $80.5(33)$ & 0.6495 & $54.0(102)$ & $46.0(87)$ & 0.0645 \\
\hline Duration (minutes) ${ }^{a}$ & $56(71)$ & $69(73)$ & 0.0290 & $55(73)$ & $64(64)$ & - \\
\hline $\begin{array}{l}\text { Sleep period starting between 00:01 and } \\
05: 59^{\mathrm{b}}\end{array}$ & $34.6(36)$ & $58.5(24)$ & 0.0084 & $31.0(45)$ & $20.7(30)$ & 0.0443 \\
\hline Sleep period between $06: 00$ and $18: 00^{b}$ & $5.8(6)$ & $9.8(4)$ & 0.3935 & $4.1(6)$ & $4.1(6)$ & 1.0000 \\
\hline \multicolumn{7}{|l|}{ Clock time (hh:mm) } \\
\hline In bed & $19: 50(2: 03)$ & $18: 14(2: 49)$ & 0.0016 & 19: $19(2: 53)$ & 19:31 (3:40) & 0.5725 \\
\hline Out of bed & $5: 18(1: 10)$ & $5: 50(2: 13)$ & 0.1544 & $5: 28(1: 50)$ & $5: 29(1: 43)$ & 0.8690 \\
\hline Sleep latency (minutes) ${ }^{\mathrm{a}}$ & $0.3(0.7)$ & $0.5(0.7)$ & 0.9440 & $0.4(0.8)$ & $0.3(1.0)$ & 0.6890 \\
\hline \multicolumn{7}{|l|}{ Sufficient sleep categories ${ }^{b}$} \\
\hline \multicolumn{7}{|l|}{ Total sleep time } \\
\hline$<7$ h/day & $33.7(35)$ & $41.5(17)$ & 0.6669 & $35.9(52)$ & $40.0(58)$ & 0.7647 \\
\hline 7-9 h/day & $51.0(53)$ & $43.9(18)$ & & $47.6(69)$ & $44.1(64)$ & \\
\hline$>9$ h/day & $15.4(16)$ & $14.6(6)$ & & $16.6(24)$ & $15.9(23)$ & \\
\hline \multicolumn{7}{|l|}{ Nocturnal sleep time } \\
\hline$<7 \mathrm{~h} /$ night & $46.2(48)$ & $56.1(23)$ & 0.4904 & $47.6(69)$ & $44.8(65)$ & 0.6954 \\
\hline 7-9 h/night & $50.0(52)$ & $39.0(16)$ & & $48.3(70)$ & $49.0(71)$ & \\
\hline$>9 \mathrm{~h} /$ night & $3.8(4)$ & $4.9(2)$ & & $4.1(6)$ & $6.2(9)$ & \\
\hline \multicolumn{7}{|l|}{ Quality } \\
\hline Wake after sleep onset (minutes) & $53(16)$ & $44(17)$ & 0.0022 & $51(18)$ & $50(20)$ & 0.8219 \\
\hline Number of awakenings & $15(4)$ & $12(4)$ & 0.0011 & $14(5)$ & $14(5)$ & 0.9577 \\
\hline Average awakening length (minutes) & $3.8(1.0)$ & $4.1(1.6)$ & 0.3339 & $4.0(1.4)$ & $3.9(1.5)$ & 0.5015 \\
\hline Sleep efficiency (\%) & $87.7(4.2)$ & $89.6(4.5)$ & 0.0225 & $88.1(4.6)$ & $88.4(4.9)$ & 0.2440 \\
\hline Achieved $\geq 85 \%^{\mathrm{b}}$ & $79.8(83)$ & $82.9(34)$ & 0.6683 & $75.9(110)$ & $76.6(111)$ & 0.8903 \\
\hline Within-person sleep time SD (minutes) ${ }^{\mathrm{a}}$ & $85.1(48.5)$ & $90.6(80.9)$ & 0.2480 & $84.3(60.8)^{d}$ & $66.2(63.2)^{d}$ & - \\
\hline Movement index (\%) & $15.5(3.8)$ & $16.6(3.6)$ & 0.1266 & $16.0(4.0)$ & $15.5(4.4)$ & 0.0617 \\
\hline Fragmentation index (\%) & $11.0(4.4)$ & $11.3(4.2)$ & 0.7219 & $11.4(4.7)$ & $10.7(5.7)$ & 0.1755 \\
\hline Sleep fragmentation index (\%) & $26.6(7.1)$ & $27.9(6.8)$ & 0.2986 & $27.4(7.4)$ & $26.2(8.7)$ & 0.0458 \\
\hline VM average counts & $34,847(12,090)$ & $27,495(10,686)$ & 0.0006 & $33,042(13,162)$ & $31,966(13,767)$ & 0.2951 \\
\hline
\end{tabular}

Italicized $p$ values are significant $(p<0.05)$

Data reported as mean (SD)

SD standard deviation, VM Vector Magnitude

${ }^{a}$ Median (IQR) or ${ }^{b} \%(n) ;{ }^{c} n$ differs from column totals; ${ }^{d} \mathrm{n}$ differs from column totals 142 and 141, respectively; Diurnal: 06h00-18h00; Nocturnal: 18h01-05h59

contrast, our objective-measure showed approximately $2 \mathrm{~h}$ lower TST for both genders compared with selfreport measures. In agreement with some self-report studies [4, 14], females recorded more nocturnal sleep time than males.

Our results for sufficient sleep (46.9\%) fell within the range reported for self-report measures (38-64.2\%) [4,
$6,7,10,28]$. In contrast, we found a higher prevalence for short sleep $49.0 \%$ vs. 5.7-20.8\%) and a lower prevalence for long sleep (4.1\% vs. $29.5-54.8 \%)$ than self-report measures, respectively $[6-8,10]$.

Sleep quantity was similar, but sleep quality was better in this study, compared with rural Mozambicans 

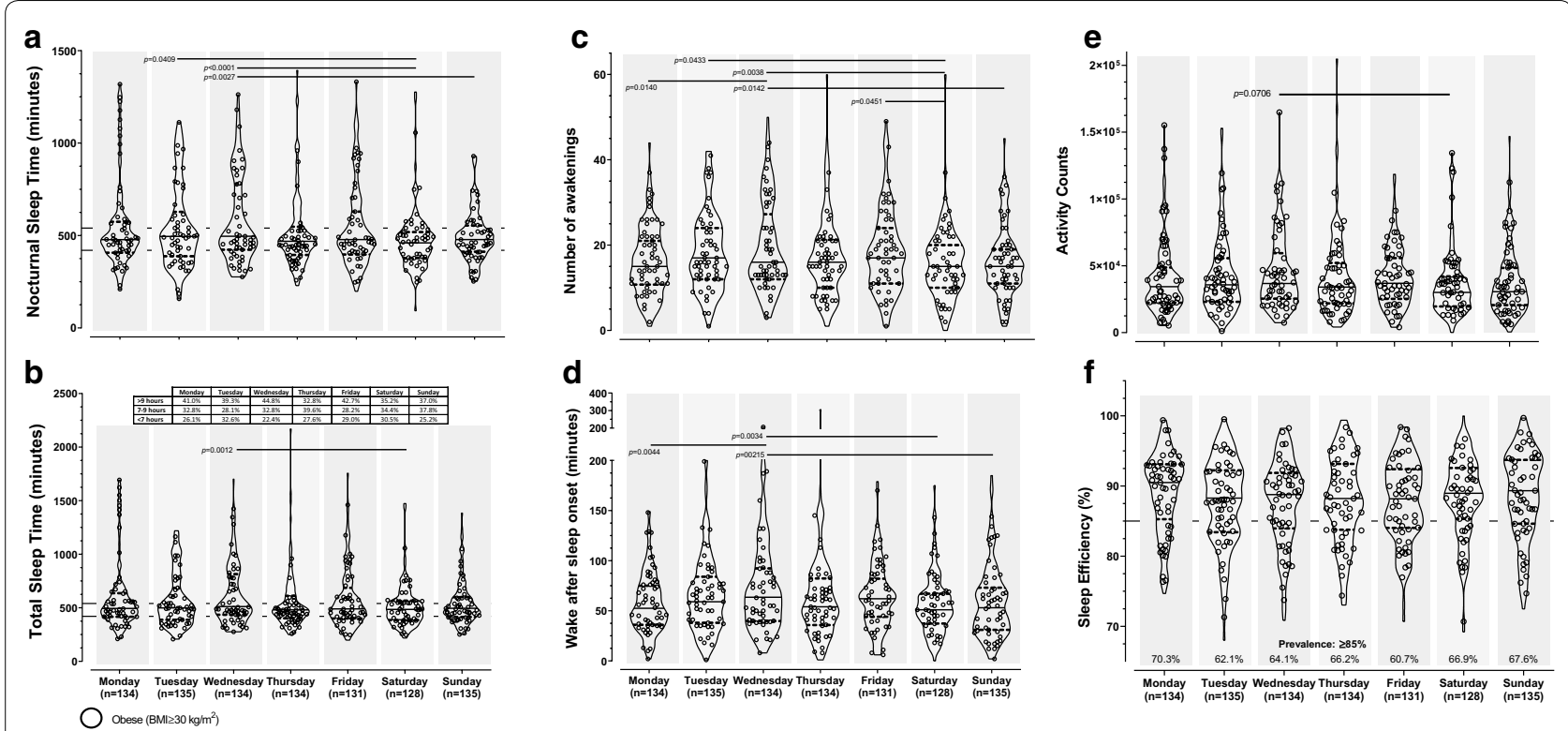

Fig. 1 Accelerometry-derived sleep-quantity and -quality measures across days of the week. a Nocturnal sleep time (minutes); b Total sleep time (minutes); c Number of awakenings; $\mathbf{d}$ Wake after sleep onset (minutes); e Activity counts during sleep time; f Sleep efficiency (percentage). The day-by-day sleep indices are presented using violin plots (medium smoothing). The horizontal lines above the day of the week indicate significant post hoc differences (Tukey procedure) between days at either end of the line

[13]. Sri Lankan adults slept less than our sample, but at similar levels of sleep quality [34].

Untreated HIV + status was associated with poor sleep quality in rural Africans [4], which is somewhat in agreement with our results.

Sleep variables were not significantly and consistently related to adiposity. Self-report measures have found significant associations between TST and blood pressure [4, 6], insulin resistance [10] and adiposity [9].

The variability in South African sleep data is likely because of differences in social, cultural, economic and environmental factors $[4,10,13]$. Indeed, we found a direct relationship between sleep duration and SES, while Gomez-Olive et al. found an inverse relationship [4], highlighting the need for contextual, qualitative data. Our preliminary qualitative data has highlighted a number of themes which will require further investigation.

In conclusion, this report presents some of the first objectively-measured, free-living sleep data from a South African setting, and highlights the need to understand the contextual issues around sleep in this rural population.

\section{Limitations}

Due to the small sample size and cross-sectional, convenience sampling in this study, the results cannot be readily generalized to the rural populations from whence the participants were recruited, nor can causality be shown.

\section{Supplementary information}

Supplementary information accompanies this paper at https://doi. org/10.1186/s13104-020-05153-8.

Additional file 1: Table S1. Forced multiple linear regression models for anthropometric variables. Table S2. Backward-selection multiple linear regression models for anthropometric variables. Table S3. Forced multiple linear regression models for sleep variables. Table S4. Backward-selection multiple linear regression models for sleep variables.

Additional file 2: Informant_Consultation.docx. Qualitative feedback from the Informant Consultation interview.

\section{Abbreviations}

AWI-Gen: Africa Wits-INDEPTH partnership for Genomics studies; BMI: Body Mass Index; Cl: Conicity Index; DHDSS: Dikgale Health and Demographic Surveillance System; NOA: Number of awakenings; PA: Physical activity; SE: Sleep efficiency; SFI: Sleep fragmentation index; TST: Total sleep time; WASO: Wake after sleep onset.

\section{Acknowledgements}

The authors would like to thank the communities, participants and field workers of the Dikgale Demographic and Health Surveillance System Site.

\section{Authors' contributions}

IC was the principal investigator of the accelerometer data on which this manuscript is based, who initiated the research and obtained funding, cowrote and edited the research proposal, supervised the data entry, analyzed 
the data and wrote the first draft manuscript. MM co-wrote and edited the research proposal, collected field data, supervised the field work, performed the data entry, commented on- and contributed to the manuscript. MA was the principal site-investigator of the AWI-Gen Phase 1 study, co-wrote and edited the research proposal, and commented on- and contributed to the manuscript. All authors read and approved the final manuscript.

\section{Funding}

The AWI-Gen Collaborative Centre is funded by the National Human Genome Research Institute (NHGRI), Office of the Director (OD), Eunice Kennedy Shriver National Institute Of Child Health \& Human Development (NICHD), the National Institute of Environmental Health Sciences (NIEHS), the Office of AIDS research (OAR) and the National Institute of Diabetes and Digestive and Kidney Diseases (NIDDK), of the National Institutes of Health (NIH) under award number U54HG006938 and its supplements, as part of the H3Africa Consortium. Additional funding was leveraged from the Department of Science and Technology, South Africa, award number DST/CON 0056/2014, and from the African Partnership for Chronic Disease Research (APCDR). The accelerometry section of this study was funded by the Competitive Programme for Rated Researchers, National Research Foundation, South Africa, award number CPRR14080687621.

\section{Availability of data and materials}

The dataset analysed during the current study is available from the corresponding author on reasonable request.

\section{Ethics approval and consent to participate}

Ethics approval for the AWI-Gen Phase 1 survey data and the accelerometer data collection was obtained from the Medunsa Research and Ethics Committee of the University of Limpopo (MREC/HS/195/2014:CR). The participants recruited into the original studies were informed about the study objectives, expected outcomes, benefits and the risks associated with it. Written informed consent was obtained from the participants prior to interviews and measurements.

\section{Consent for publication}

Not applicable.

\section{Competing interests}

The authors declare no competing interests.

\section{Author details}

${ }^{1}$ Physical Activity Epidemiology Laboratory (EDST), University of Limpopo (Turfloop Campus), Sovenga, PO Box X1106, Limpopo 0727, South Africa.

${ }^{2}$ Department of Pathology and Medical Sciences, University of Limpopo (Turfloop Campus), Sovenga, Limpopo, South Africa.

Received: 13 February 2020 Accepted: 25 June 2020

Published online: 01 July 2020

\section{References}

1. St-Onge M-P, Grandner MA, Brown D, Conroy MB, Jean-Louis G, Coons $M$, et al. Sleep duration and quality: impact on lifestyle behaviors and cardiometabolic health: a scientific statement from the American Heart Association. Circulation. 2016;134:e367-86.

2. Simonelli G, Marshall NS, Grillakis A, Miller CB, Hoyos CM, Glozier N. Sleep health epidemiology in low and middle-income countries: a systematic review and meta-analysis of the prevalence of poor sleep quality and sleep duration. Sleep Health. 2018;4:239-50.

3. Cole HV, Owusu-Dabo E, Iwelunmor J, Newsome V, Meeks K, Agyemang $C$, et al. Sleep duration is associated with increased risk for cardiovascular outcomes: a pilot study in a sample of community dwelling adults in Ghana. Sleep Med. 2017;34:118-25.

4. Gomez-Olive FX, Rohr JK, Roden LC, Rae DE, von Schantz M. Associations between sleep parameters, non-communicable diseases, HIV status and medications in older, rural South Africans. Sci Rep. 2018;8:17321.

5. Gomez-Olive FX, Thorogood M, Kandala NB, Tigbe W, Kahn K, Tollman S, et al. Sleep problems and mortality in rural South Africa: novel evidence from a low-resource setting. Sleep Med. 2014;15:56-63.
6. Gradidge P, Merling P, Cohen E. The determinants of overweight/obesity and blood pressure in rural South African women living in the Tshino Nesengani (Mukondeleli) village. S Afr J Sports Med. 2018;30:1-5.

7. Peltzer K. Sociodemographic and health correlates of sleep problems and duration in older adults in South Africa. S Afr J Psychiatr. 2012;18:150-6.

8. Peltzer K. Differences in sleep duration among four different population groups of older adults in South Africa. Int J Environ Res Public Health. 2017; 14:502.

9. Pretorius S, Stewart S, Carrington MJ, Lamont K, Sliwa K, Crowther NJ. Is there an association between sleeping patterns and other environmental factors with obesity and blood pressure in an urban African population? PLOS ONE. 2015;10:e0131081.

10. Rae DE, Pienaar PR, Henst RHP, Roden LC, Goedecke JH. Associations between long self-reported sleep, obesity and insulin resistance in a cohort of premenopausal black and white South African women. Sleep Health. 2018:4:558-64.

11. Szalontai G. The demand for sleep: a South African study. Econ Model. 2006;23:854-74.

12. Sani $M$, Refinetti $R$, Jean-Louis $G$, Pandi-Perumal SR, Durazo-Arvizu RA, Dugas LR, et al. Daily activity patterns of 2316 men and women from five countries differing in socioeconomic development. Chronobiol Int. 2015;32:650-6.

13. Beale AD, Pedrazzoli M, Gonçalves BSB, Beijamini F, Duarte NE, Egan KJ, et al. Comparison between an African town and a neighbouring village shows delayed, but not decreased, sleep during the early stages of urbanisation. Sci Rep. 2017;7:5697.

14. Mashinya F, Alberts M, Cook I, Ntuli S. Determinants of body mass index by gender in the Dikgale Health and Demographic Surveillance System site South Africa. Glob Health Action. 2018;11:1537613.

15. Alberts M, Dikotope SA, Choma SR, Masemola ML, Modjadji SE, Mashinya F, et al. Health \& demographic surveillance system profile: the dikgale health and demographic surveillance system. Int J Epidemiol. 2015:44:1565-71.

16. Ali SA, Soo C, Agongo G, Alberts M, Amenga-Etego L, Boua RP, et al. Genomic and environmental risk factors for cardiometabolic diseases in Africa: methods used for Phase 1 of the AWI-Gen population crosssectional study. Glob Health Action. 2018;11:1507133.

17. Valdez R, Seidell JC, Ahn Yl, Weiss KM. A new index of abdominal adiposity as an indicator of risk for cardiovascular disease. A cross-population study. Int J Obes Relat Metab Disord. 1993;17:77-82.

18. Whitaker KM, Pettee Gabriel K, Jacobs DR Jr, Sidney S, Sternfeld B. Comparison of two generations of ActiGraph accelerometers: the CARDIA Study. Med Sci Sports Exerc. 2018;50:1333-40.

19. Migueles JH, Cadenas-Sanchez C, Ekelund U, Delisle Nyström C, MoraGonzalez J, Löf M, et al. Accelerometer data collection and processing criteria to assess physical activity and other outcomes: a systematic review and practical considerations. Sports Med. 2017:47:1821-45.

20. Slater JA, Botsis T, Walsh J, King S, Straker LM, Eastwood PR. Assessing sleep using hip and wrist actigraphy. Sleep Biol Rhythms. 2015;13:172-80.

21. Full KM, Kerr J, Grandner MA, Malhotra A, Moran K, Godoble S, et al. Validation of a physical activity accelerometer device worn on the hip and wrist against polysomnography. Sleep Health. 2018;4:209-16.

22. Cole RJ, Kripke DF, Gruen W, Mullaney DJ, Gillin JC. Automatic sleep/wake identification from wrist activity. Sleep. 1992;15:461-9.

23. What is the "Detect Sleep Periods" button in Sleep Analysis? https://actig raphcorp.force.com/support/s/article/What-does-the-Detect-Sleep-Perio ds-button-do-and-how-does-it-work. Accessed 10 Feb 2020.

24. Tudor-Locke C, Barreira TV, Schuna JM Jr, Mire EF, Katzmarzyk PT. Fully automated waist-worn accelerometer algorithm for detecting children's sleep-period time separate from 24-h physical activity or sedentary behaviors. Appl Physiol Nutr Metab. 2013;39:53-7.

25. Choi L, Liu Z, Matthews CE, Buchowski MS. Validation of accelerometer wear and nonwear time classification algorithm. Med Sci Sports Exerc. 2011;43:357-64.

26. Choi L, Ward SC, Schnelle JF, Buchowski MS. Assessment of wear/nonwear time classification algorithms for triaxial accelerometer. Med Sci Sports Exerc. 2012;44:2009-16.

27. Wennman $H$, Pietilä A, Rissanen $H$, Valkeinen $H$, Partonen $T$, Mäki-Opas T, et al. Gender, age and socioeconomic variation in 24-hour physical activity by wrist-worn accelerometers: the FinHealth 2017 Survey. Sci Rep. 2019:9:6534. 
28. Ancoli-Israel S, Martin JL, Blackwell T, Buenaver L, Liu L, Meltzer LJ, et al. The SBSM guide to actigraphy monitoring: clinical and research applications. Behav Sleep Med. 2015;13:S4-38.

29. Chung S, Youn S, Lee C, Jo M-W, Park J, Jo SW, et al. Environmental noise and sleep disturbance: night-to-night variability of sleep/wake pattern. Sleep Med Res. 2016;7:78-81.

30. Ko Y, Lee J-Y. Effects of feet warming using bed socks on sleep quality and thermoregulatory responses in a cool environment. J Physiol Anthropol. 2018;37:13.

31. Hirshkowitz M, Whiton K, Albert SM, Alessi C, Bruni O, DonCarlos L, et al. National Sleep Foundation's sleep time duration recommendations: methodology and results summary. Sleep Health. 2015;1:40-3.

32. Fung MM, Peters K, Ancoli-Israel S, Redline S, Stone KL, Barrett-Connor E. Total sleep time and other sleep characteristics measured by actigraphy do not predict incident hypertension in a cohort of community-dwelling older men. J Clin Sleep Med. 2013;9:585-91.

33. Ding D, Sallis JF, Hovell MF, Du J, Zheng M, He H, et al. Physical activity and sedentary behaviours among rural adults in Suixi, China: a cross-sectional study. Int J Behav Nutr Phys Act. 2011;8:37.

34. Schokman A, Bin YS, Simonelli G, Pye J, Morris R, Sumathipala A, et al. Agreement between subjective and objective measures of sleep duration in a low-middle income country setting. Sleep Health. 2018;4:543-50.

\section{Publisher's Note}

Springer Nature remains neutral with regard to jurisdictional claims in published maps and institutional affiliations.
Ready to submit your research? Choose BMC and benefit from:

- fast, convenient online submission

- thorough peer review by experienced researchers in your field

- rapid publication on acceptance

- support for research data, including large and complex data types

- gold Open Access which fosters wider collaboration and increased citations

- maximum visibility for your research: over 100M website views per year

At BMC, research is always in progress.

Learn more biomedcentral.com/submissions 